\title{
Has Hiroshima Bombing Continued?
}

\author{
Yohannes Hawaz, Tesfaye Kebede, \\ $M D$, senior radiologist, $M D$, consultant radiologist, \\ Addis Ababa University, faculty of medicine, department of radiology
}

\begin{abstract}
There is increased use of nuclear energy after the Second World War which results in increase in artificial radioactivity on our planet. The objective of this article is to show the estimated amount of artificial radioactivity on earth surface and its effect by comparing it with the radioactive decay which took place in Hiroshima bombing by 'little boy'. There is estimated amount of 100 trillion curie of radioactivity on earth surface for human use. This man made radioactivity on earth surface has capacity to change temperature of the earth by $0.97^{\circ} \mathrm{C}$ if heat is evenly distributed and unfortunately Hiroshima bombing did not stop but continued at rate of 39 'little boy' bombing of the earth per second. Every second 39 atomic bombs of 'little boy' size are dropped. One can see the large amount of bombing taking place on the earth by artificial radioactivity and the bombing should be stopped and further analysis of artificial radioactivity should also be done.
\end{abstract}

Key words: nuclear energy, radioactivity

\section{Introduction}

Atomic nucleus has huge amount of energy which is not comparable with other forms of energy. With small amount of mass use result in production of significantly large amount of energy from the nucleus of an atom. The famous formula $\mathrm{E}=\mathrm{mc}^{2}$ is designed by Einstein to demonstrate the huge amount of energy produced by the small amount of mass.

After the Second World War civilian and military use of nuclear energy is markedly increasing. The civilian source of nuclear energy affects the planet in two ways. Directly heat is produced by nuclear reactors which have minimal efficiency and the indirect effect of civilian source of nuclear energy is by large amount of nuclear waste production. It is in hundreds of millions kilogram of high level wastes which has output of huge amount of heat and radiations. The military sources of nuclear energy are nuclear bomb tests and lost nuclear missiles in the ocean.

Bomb detonated in Hiroshima and Nagasaki during the second world war resulted in devastating result on human being and the environment and it is still a reason for debate whether it was reasonablely done or not but one has to learn from the past and what should not be done in the past should not be repeated at present.

A question should be answered 'what was done in Hiroshima is repeated?' To what extent is being done on Earth?

\section{Radioactive decay of atomic bomb in Hiroshima :}

\section{Facts}

Bombing of Hiroshima design used gun method and uranium-235 underwent fission reaction which exploded by initiating nuclear chain reaction. The bomb 'little boy' contained $64 \mathrm{~kg}$ of uranium, of which less than a kilogram underwent nuclear fission, and of this mass only $0.6 \mathrm{~g}$ was transformed into energy[1] .

Manhattan Project scientists were so confident in the performance of the "Little Boy" uranium bomb that the device was not even tested before it was used. This 15-kt(63TJ) weapon was airdropped on 06 August 1945 at Hiroshima, Japan. The device contained $64.1 \mathrm{~kg}$ of highly enriched uranium, with an average enrichment of $80 \%[2]$.

Specific activity of Uranium-235 is $80,011 \mathrm{~Bq} / \mathrm{gm}$ on alpha decay [3].

Uranium-235 has half-life of 704million years and alpha decay produce $4.5 \mathrm{MeV}$ energy[4].

Typical fission reaction of U-235 produce energy of $200 \mathrm{MeV}$ [5].

Only 0.6 gm of Uranium-235 transform to energy when 'little boy' was detonated in Hiroshima and double (1.2gm) amount of Uranium-235 which undergo alpha decay in 704million years times the ratio of energy found by U-235 fission reaction and alpha decay give the same amount radioactivity of 'little boy'.

$1.2 \mathrm{gm} \mathrm{x} 80,011 \mathrm{~Bq} / \mathrm{gm} \quad=96,013.2 \mathrm{~Bq}$.

Half life of U-235 is 704million years $=2.22 \times 10^{16}$ seconds.

Total radioactivity $0.6 \mathrm{gm}$ of $\mathrm{U}-235$ by alpha decay is $2.13 \times 10^{21} \mathrm{~Bq}$.

When multiplied by the ratio energy of fission reaction and alpha decay of U-235 200/4.5:

$2.13 \times 10^{21} \mathrm{~Bq} \times 200 / 4.5=9.47 \times 10^{22} \mathrm{~Bq}$ 
Fission reaction of $0.6 \mathrm{gm}$ uranium made radioactivity of 'little boy' $9.47 \times 10^{22} \mathrm{~Bq}$.

Same amount of U-235 in little boy undergoing fission reaction give same amount of energy given by $9.47 \mathrm{x}$ $10^{22} \mathrm{~Bq}$ radioactivity.

\section{Radioactive decay of earthly artificial activity :}

According to Lorna Salzman the Hanford tanks, with about 71million galloons of neutralized highlevel liquid wastes have a dismal history. Over the thirty years of military activities, 450,000 galloons of highlevel waste have leaked into the soil and in some areas in to the ground water beneath the reservation which adjoins the Columbia River. The high-level wastes in the Hanford tanks contain up to 10,000 curies of radioactivity per gallon [6].

There is about 0.71 trillion curie radioactivity in Hanford tanks which is about one trillion curie of activity in single place and may be there are more than 1000 places of high level radioactive waste disposal sites in our planet.

Estimates of the radiation released from Chernobyl incident range from 50 Million curies to 4.5 Billion curies of radiation. [7]:The World Health Organization (WHO) has estimated that the total radioactivity from Chernobyl was 200 times that of the combined releases from the atomic bombs dropped on Hiroshima \& Nagasaki[8]. The Chernobyl incident results in average 2.275billion curies of activity. Hanford tanks result in 312.1 times radioactivity every second when compared to Chernobyl incident and 62,420 times radioactivity take place in Hanford when compared from the atomic bombs dropped on Hiroshima \& Nagasaki. It means 62,420 bombs which have size of atomic bombs dropped on Hiroshima \& Nagasaki are dropped by Hanford tanks every second.

\section{Estimated amount of radioactivity on earth surface:}

1/ The Hanford incident and reckless storage of HLW in many countries [9] one can estimate up to: 65 trillion curie of radioactivity from radioactive wastes (minimum),

2/ In 2007, IAEA reported there were 439 nuclear power reactors in operation in the world,[10], operating in 31 countries[11]. There are also fleets and other machines which use atomic energy. Efficiency of nuclear reactor is low and most of the heat is released to the ocean. The activity of each reactor and capacity not stated but each reactor may have up to 57 billion curie of activity:

25 trillion curie from power generating nuclear reactors,

3 / From single atomic bomb test less than $1 \%$ radionuclide is used and the rest is released to the earth surface in its pure form. How many tests done? Nobody knows.

10 trillion curie from nuclear bomb tests and lost nuclear missiles in the oceans.

If there is minimum 100 trillion curie of artificial radioactivity on earth surface:

100 trillion curie of activity $=3.7 \times 10^{24} \mathrm{~Bq}$.

Total number of detonating 'little boys' on earth surface are:

$3.7 \times 10^{24} \mathrm{~Bq} / 9.4710^{22} \mathrm{~Bq}=39.07$ detonations every second.

Single detonation of little boy produced $63 \mathrm{TJ}$ of energy.

39.07 detonations produce energy of $2.46 \times 10^{15} \mathrm{~J}$.

$2.46 \times 10^{15} \mathrm{~J}=2.46 \times 10^{15} \mathrm{Watt} / \mathrm{sec}$.

Surface area of the earth $=5.1 \times 10^{14}$ metersquare[12].

If power is evenly distributed on earth surface $4.82 \mathrm{watt} /$ meter square reach from artificial radioactivity.

Solar irradiation to the earth is 164 watt/ square meter [13] and it can maintain average atmospheric temperature $33^{\circ} \mathrm{C}$ more than it should be.

If average $164 \mathrm{watt} /$ square meter irradiation give $33^{\circ} \mathrm{C}[14]$ then 4.82 watt/square meter additional power supply to the earth surface increase atmospheric temperature by $0.97^{\circ} \mathrm{C}$.

Man made radioactivity on earth surface has capacity to change temperature of the earth by $0.97^{\circ} \mathrm{C}$ if heat is evenly distributed. Unfortunately Hiroshima bombing did not stop but continued at rate of 39 'little' boy bombing of the earth per second.

Further analysis of artificial radioactivity and its effect should be done as there is no any clear periodic report done by concerned body and bombing of the planet should also be stopped. Every body should also stand against atomic bombing of the planet. 


\section{References}

[1]- Glasstone, S., Dolan, P. J., 1977: The Effects of Nuclear Weapons, 3rd Ed. Department of Defense, Department of Energy.

[2]- Nuclear Weapons Technology Military Critical Technologies List (MCTL) PART II: Weapons of mass destruction technologies and NATO handbook on the medical aspects of NBC defensive operations part I-Nuclear October 211998.

[3]- Peter D. WISE Uranium project, Uranium radiation properties Jan 29, 2010., http://www.wise-uranium.org

[4]- Paul Zimmerman, introduction, A Primer In The Art of deception The cult of nuclearists, uranium weapons and fraudulent science, 2009.

[5]- Nuclear energy, Health Physics Society, February $22^{\text {nd }}, 2009$ http://www.hps.org/publicinformation/ate/faqs/radiationtypes.html

[6]- Lorna Salzman, Wasting Away: Radioactive Waste Disposal is the Achilles Heel of the Nuclear Industry , New Ecologist, Number 6, Nov/Dec 1978.

[7] John M. LaForge, Chernobyl : A Global Tragedy. Earth Island Journal. Summer 1997.

[8] Fairlie, Ian, The TORCH Report Executive Summary. UK \& Sumner, David UK . 2006. Commissioned by The Greens EFA in the European Parliament.

[9] Kevin Crowley, John F. AhearneManaging the Environmental Legacy of U.S. AMERICAN scientist,Nuclear-Weapons Production, November-December 2002 Volume 90, Number 6,Page: 514.

[10] "Nuclear Power Plants Information. Number of Reactors Operation Worldwide". International Atomic Energy Agency. http://www.iaea.org/cgi-bin/db.page.pl/pris.oprconst.htm. 2008-06-21.

[11] "World Nuclear Power Reactors 2007-08 and Uranium Requirements". World Nuclear Association. 2008-06-09. http://www.uic.com.au/reactors.htm. Retrieved 2008-06-21.

[12]- Fraser Cain, Surface area of the earth, Universe today 2010. http://www.universetoday.com/

[13] Garry Fletcher, Solar Energy at Race Rocks, RACEROCKS.COM,2010. Lester B. Pearson College of the Pacific.

[14] Pidwirny, M. (2006). "The Greenhouse Effect". Fundamentals of Physical Geography, 2nd Edition. http:/www.physicalgeography.net/fundamentals/7h.html 